\title{
Pressure-Flow Studies in Man during Atrial Fibrillation
}

\author{
Joseph C. Greenfield, Jr., Alexander Harley, Howard K. Thompson, \\ and ANDrew G. WALLACE \\ From the Department of Medicine, Division of Cardiology, Duke University \\ Medical Center, and the Durham Veterans Administration Hospital, \\ Durham, North Carolina 27705
}

A в S T R A C T In 13 patients who had atrial fibrillation the ascending aortic pressure-flow relationships were measured by the pressure gradient technique. Both the pressure and flow curves were similar in contour to ones previously obtained by this method. From these recordings, relationships between the phases of systole, the ventricular filling time, and various derived parameters of pressure and flow such as the pulse pressure, stroke volume, peak flow, stroke work, and peak power were evaluated. For stroke volumes greater than 15 $\mathrm{cm}^{3}$ there was little change in the duration of systole in an individual patient. In each patient both the preejection period and the duration of ejection showed a good correlation with stroke volume, peak flow, stroke work, and peak power. When data from all patients were examined, the relationship between stroke volume and duration of ejection was found to be curvilinear and had an overall correlation of $r=0.91$. There was marked variation from patient to patient in duration of both the preejection period and systole. Similar correlations between the phases of systole were noted with peak flow, peak power, and stroke work. A positive but mediocre correlation was found between the previous RR interval (an index of ventricular filling time) and the subsequent stroke volume. The correlation, in six patients, between two previous RR intervals and stroke volume was considerably better. The relationship between the pulse pressure and stroke volume was reasonably close except in one patient; however, the group correlation was poor due to differences between individuals.

Received for publication 9 May 1968 and in revised form 25 June 1968.

\section{INTRODUCTION}

Atrial fibrillation alters cardiac performance both by removing the hemodynamic consequences of atrial contraction and by imposing an irregular variation in ventricular cycle length. Since the presence of this arrhythmia offers an opportunity to examine the effects of beat to beat variations in both ventricular filling and ejection, it has been of interest to circulatory physiologists as well as clinicians. Cardiac output in patients with atrial fibrillation has been studied by many investigators before and after conversion to normal sinus rhythm. A recent review of these studies concluded that atrial fibrillation usually is associated with reduced cardiac performance (1). However, the inability to measure accurately and continuously either phasic aortic blood flow or left ventricular volume in man has limited the scope of previous work on the hemodynamics of atrial fibrillation. In particular, no definition of the beat to beat relationship between stroke volume and the duration of the phases of cardiac systole has been formulated.

The recent development of the pressure gradient technique (2) has made it possible to measure continuously aortic blood flow and pressure in the intact human subject. This report presents hemodynamic data obtained from a group of patients who have atrial fibrillation and further examines the effects of this arrhythmia on the characteristics of cardiac ejection.

\section{METHODS}

Blood pressure and flow in the ascending aorta were recorded continuously in 13 male patients. Each had an electrocardiographic diagnosis of atrial fibrillation, and 
all were hospitalized at the Durham Veterans Administration Hospital. These measurements were made during the course of routine cardiac catheterization carried out to assess either valvular or coronary artery heart disease. The informed consent of each patient was obtained before study. All of the patients were receiving a maintenance dose of digitalis at the time of the study. The pertinent clinical data describing these patients are listed in Table I.

The phasic blood pressure and flow were estimated in the ascending aorta by the pressure gradient technique (2). This method is based on an approximate solution of the Navier-Stokes equations of fluid motion. The technique has been experimentally evaluated in both a flow generator (3) and in the dog aorta (4) and found to yield a valid estimate of phasic flow. The technique has been applied sucessfully in this laboratory $(5,6)$ and by other investigators (7-9) to measure pulsatile blood pressure and flow in the ascending aorta of the intact human subject. The instrumental techniques, manometric accuracy requirements, and calibration procedures used in our laboratory to obtain valid phasic flow and pressure data in man have been previously described in detail and will only be reviewed briefly $(10,11)$.

A specially designed 6.5 French double lumen catheter 1 with lateral pressure taps separated by $4 \mathrm{~cm}$ was used to measure the blood pressure at two points in the ascending aorta. The catheter was inserted percutaneously into the femoral artery and advanced under fluoroscopic control until the tip was about $2 \mathrm{~cm}$ above the aortic valve. An analogue computer ${ }^{2}$ was used to obtain the pressure difference and to continuously compute phasic blood flow (10). Pressure from the distal lumen of the catheter also was recorded. Blood pressure and flow were measured simultaneously in all patients for approximately $5 \mathrm{~min}$. During this period the cardiac output was obtained by an indicator dilution technique with Indocyanine green dye injected through a second cardiac catheter into the pulmonary artery and sampled from a brachial artery. The electrocardiogram was recorded throughout the study. Since an estimate of the aortic radius is necessary to calibrate the pressure gradient technique for flow, aortography was carried out during the procedure by a previously described technique (6). All data were recorded on an optical recorder ${ }^{3}$ at a paper speed of $100 \mathrm{~mm} / \mathrm{sec}$ and on an electromagnetic tape recorde:-4

In evaluating the data, from 25 to 60 separate heart beats were selected from each patient. Tracings in which the stroke volume varied widely were chosen and in six patients consecutive heart beats were found to be technically acceptable. The systolic, diastolic, and pulse pressures were measured directly from the pressure recordings. Zero flow was assumed to be present at the end of diastole. Planimetric integration of the flow tracing was

1 U. S. Catheter \& Instrument Corp., Glens Falls, N. Y.

2 Model 3400 Analog Computer, Systron-Donner Corporation, Con'ord, Calif.

${ }^{3}$ Model DR8 Electronics for Medicine, Inc., White Plains, N. Y.

${ }^{4}$ Model 2000, Sanborn Co., Waltham, Mass. carried out to obtain stroke volume. Peak flow was measured as the maximal amplitude of the flow recording. The duration of systole (DS) was measured as the period from the onset of the $Q$ wave of the electrocardiogram to the end of forward flow as shown in Fig. 1. Duration of ejection (DE) was taken as the duration of forward flow. The preejection period (PEP) was calculated from the duration of systole minus the duration of ejection. The per cent of the stroke volume which occurred during the first half of ejection was measured planimetrically from the flow tracing and expressed as a per cent of the total stroke volume. Peak power was the maximal value of the product of blood pressure and flow (measured every $0.01 \mathrm{sec}$ ). The time at which peak power occurred was expressed as a per cent of the duration of ejection. Pressure energy, i.e. stroke work, was computed as the product of stroke volume and mean systolic pressure. Since it is known to be quite small, the kinetic energy was not computed. The previous $R R$ interval was measured from the electrocardiogram. Theoretical heart rate (HR) was computed for each preceding cycle length ( $R R$ interval) by the expression $H R=$ $60 /$ RR. All plotting of data as well as the statistical analysis was carried out on a digital computer. ${ }^{5}$

\section{RESULTS}

The 13 patients studied represent a broad spectrum of cardiac disease and functional state (Table I). Although each patient was receiving maintenance digitalis, the heart rate in eight was greater than 100 beats/min, indicating that they were probably not fully digitalized.

The cardiac outputs obtained by the indicator dilution method are not strictly comparable with those measured by the pressure gradient technique since they were not recorded simultaneously. In five patients in whom both consecutive flow data and indicator dilution cardiac outputs were available, the control cardiac output (computed from the average stroke volume for a $20 \mathrm{sec}$ period) had a mean value of $3,500 \mathrm{~cm}^{3} / \mathrm{min}$, while a mean of $3300 \mathrm{~cm}^{3} / \mathrm{min}$ was obtained by the indicator dilution method. The mean value for the difference between the two methods was $170 \pm \operatorname{SE} 200 \mathrm{~cm}^{3}$ / min.

In Table II, the ranges for the various hemodynamic parameters are listed, and a wide variation for each patient is apparent. A typical recording of pressure and flow, obtained from patient R.Y., is illustrated in Fig. 1. Note that the flow rapidly accelerates, reaching its peak value before the midpoint of ejection. The flow is main-

${ }^{5}$ Model 1130, International Business Machines Corp., New York. 
TABLE I

Clinical Data

\begin{tabular}{|c|c|c|c|c|c|c|c|}
\hline Patient & Diagnosis* & Age & Weight & Height & $\begin{array}{l}\text { N.Y. } \\
\text { Heart } \\
\text { Classi- } \\
\text { fication }\end{array}$ & $\begin{array}{l}\text { Average } \\
\text { heart } \\
\text { rate }\end{array}$ & $\begin{array}{l}\text { Cardiac } \\
\text { output }\end{array}$ \\
\hline & & $y r$ & $l b$. & in. & & $\begin{array}{c}\text { beats/ } \\
\text { min }\end{array}$ & $\begin{array}{l}\mathrm{cm}^{2} / \\
\mathrm{min}\end{array}$ \\
\hline J. S. & CAD & 53 & 122 & 67 & 3 & 88 & 3167 \\
\hline M. B. & RHD-MI & 38 & 142 & 68 & 2 & 96 & 4157 \\
\hline L. S. & Idiopathic & 53 & 132 & 65 & 2 & 102 & 3131 \\
\hline G. P. & RHD-MI & 47 & 129 & 67 & 2 & 104 & 3640 \\
\hline W. J. & Idiopathic & 57 & 123 & 60 & 1 & 118 & - \\
\hline R. J. & $\mathrm{CAD}$ & 39 & 198 & 66 & 2 & 70 & - \\
\hline R. Y. & RHD-MI & 35 & 177 & 72 & 3 & 108 & 2800 \\
\hline S. D. & IMH & 38 & 203 & 68 & 4 & 95 & 2837 \\
\hline H. H. & Idiopathic & 45 & 183 & 63 & 1 & 104 & 4605 \\
\hline L. D. & CAD & 53 & 239 & 76 & 2 & 56 & 4034 \\
\hline R. P. & Hyperthyroid & 46 & 159 & 70 & 1 & 104 & 5822 \\
\hline W. H. & RHD-MS & 45 & 125 & 65 & 2 & 112 & 3649 \\
\hline J. N. & RHD-MS & 53 & 162 & 69 & 2 & 130 & 3166 \\
\hline
\end{tabular}

* Abbreviations used in diagnosis column: CAD, coronary artery disease; RHD, rheumatic heart disease; MI, mitral insufficiency; MS, mitral stenosis; IMH, idiopathic myocardial hypertrophy. Idiopathic denotes no other heart disease was found.

$\ddagger$ Obtained by indicator dilution technique.

tained briefly at this level and then decreases rapidly during the second half of ejection. Despite beat to beat variations in stroke volume, little difference in the contour of the flow pulses can be noted. From $46-62 \%$ of the total stroke volume occurs during the first half of ejection (see Table II, column 9). In 12 patients, this fraction was independent of the size of the stroke volume. How- ever, in patient M.B., a greater per cent was ejected during the first half of ejection in the beats having a larger stroke volume. There were no characteristics of the contours of the flow pulses which could be related to the specific cardiac pathology in this group of patients.

All of the data from 13 patients (290 separate heart beats) were used to construct plots of the

TABLE II

General Hemodynamic Data

\begin{tabular}{|c|c|c|c|c|c|c|c|c|c|c|c|}
\hline & \multirow[b]{2}{*}{ Patient } & \multirow{2}{*}{$\begin{array}{c}\begin{array}{c}\text { Duration } \\
\text { systole }\end{array} \\
\text { Range }\end{array}$} & \multirow{2}{*}{$\begin{array}{c}\begin{array}{c}\text { Duration } \\
\text { ejection }\end{array} \\
\text { Range }\end{array}$} & \multirow{2}{*}{$\begin{array}{c}\begin{array}{c}\text { Previous } \\
\text { RR in- } \\
\text { terval }\end{array} \\
\text { Range }\end{array}$} & \multirow{2}{*}{$\begin{array}{c}\begin{array}{c}\text { Pulse } \\
\text { pressure }\end{array} \\
\text { Range }\end{array}$} & \multirow{2}{*}{$\begin{array}{l}\begin{array}{l}\text { Stroke } \\
\text { volume }\end{array} \\
\text { Range }\end{array}$} & \multirow{2}{*}{$\begin{array}{c}\begin{array}{c}\text { Peak } \\
\text { flow }\end{array} \\
\text { Range }\end{array}$} & \multirow{2}{*}{$\frac{\begin{array}{c}\text { Peak } \\
\text { velocity }\end{array}}{\text { Range }}$} & \multirow{2}{*}{$\begin{array}{c}\begin{array}{c}\text { Flow } \\
\text { first } \\
\text { half } \\
\text { ejection }\end{array} \\
\text { Range }\end{array}$} & \multirow{2}{*}{$\begin{array}{c}\begin{array}{c}\text { Peak } \\
\text { power }\end{array} \\
\text { Range }\end{array}$} & \multirow{2}{*}{$\begin{array}{c}\begin{array}{c}\text { Stroke } \\
\text { work }\end{array} \\
\text { Range }\end{array}$} \\
\hline & & & & & & & & & & & \\
\hline & & sec & $\mathrm{sec}$ & sec & $m m \mathrm{Hg}$ & $\mathrm{cm}^{2}$ & $\mathrm{~cm}^{3} / \mathrm{sec}$ & $\mathrm{cm} / \mathrm{sec}$ & $\%$ & $g-m / s e c$ & $g / m$ \\
\hline & J. S. & $0.310-0.340$ & $0.190-0.235$ & $0.53-0.88$ & $10-47$ & $15-51$ & $135-350$ & $20-50$ & $50-56$ & $152-511$ & $15-52$ \\
\hline & M. B. & $0.220-0.310$ & $0.090-0.250$ & $0.32-1.33$ & $7-64$ & $7-104$ & $120-670$ & $20-110$ & $48-60$ & $168-1260$ & $9-130$ \\
\hline & L. S. & $0.260-0.310$ & $0.080-0.225$ & $0.39-0.83$ & $4-66$ & $4-61$ & $60-510$ & $8-60$ & $46-52$ & $71-935$ & $5-76$ \\
\hline & G. P. & $0.295-0.320$ & $0.100-0.185$ & $0.37-0.83$ & $4-46$ & $5-31$ & $70-290$ & $9-38$ & $47-51$ & $93-540$ & $6-42$ \\
\hline & W. J. & $0.230-0.260$ & $0.135-0.200$ & $0.41-0.77$ & $13-74$ & $12-44$ & $160-420$ & $23-60$ & $46-56$ & $185-740$ & $13-48$ \\
\hline & R. J. & $0.360-0.390$ & $0.220-0.280$ & $0.65-1.47$ & $29-49$ & $38-128$ & $270-840$ & $28-88$ & $54-62$ & $457-1300$ & $52-140$ \\
\hline & R. Y. & $0.280-0.360$ & $0.115-0.260$ & $0.41-0.83$ & $6-38$ & $7-66$ & $120-440$ & $17-60$ & $50-57$ & $161-664$ & $9-78$ \\
\hline & S. D. & $0.340-0.370$ & $0.165-0.210$ & $0.44-0.79$ & $15-41$ & $15-56$ & $175-500$ & $18-50$ & $47-52$ & $227-765$ & $17-66$ \\
\hline & L. D. & $0.290-0.330$ & $0.160-0.220$ & $0.60-1.78$ & $13-42$ & $17-55$ & $190-470$ & $19-46$ & $47-58$ & $281-708$ & $23-68$ \\
\hline & H. H. & $0.290-0.335$ & $0.125-0.230$ & $0.43-1.07$ & $3-60$ & $5-70$ & $130-572$ & $20-88$ & $48-56$ & $131-1120$ & 6-95 \\
\hline & R. P. & $0.290-0.340$ & $0.110-0.240$ & $0.47-0.89$ & $4-53$ & $9-108$ & $146-840$ & $15-87$ & 48-55 & $147-621$ & $9-117$ \\
\hline & W. H. & $0.310-0.340$ & $0.140-0.225$ & $0.43-0.72$ & $6-71$ & $9-69$ & $120-505$ & $17-70$ & $47-52$ & $174-1120$ & $12-108$ \\
\hline . & J. N. & $0.260-0.300$ & $0.130-0.240$ & $0.32-0.59$ & $7-82$ & $13-94$ & $170-795$ & $22-104$ & $49-53$ & 249-1770 & $18-140$ \\
\hline
\end{tabular}




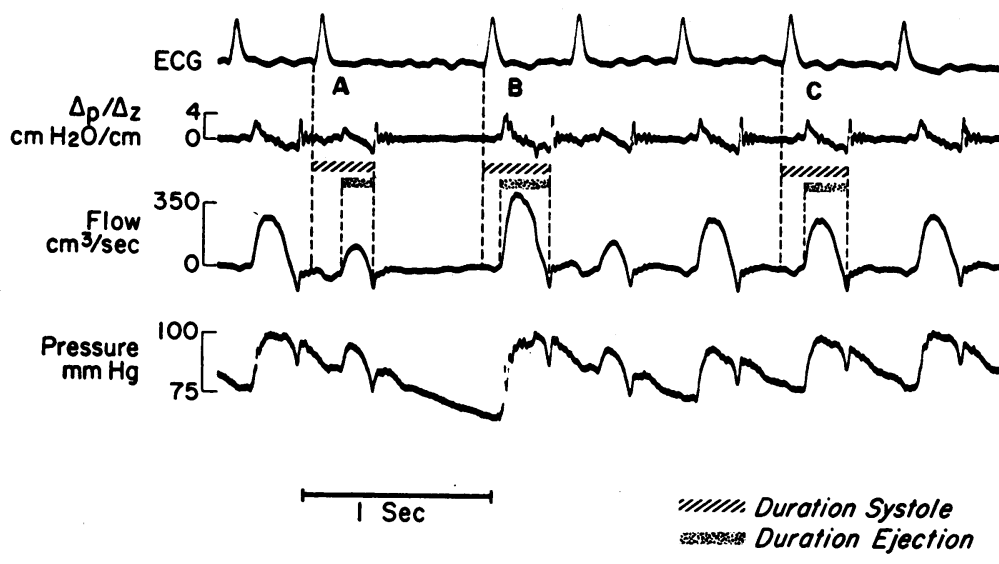

Figure 1 A typical pressure-flow recording obtained from patient R.Y. From the top down, the electrocardiogram, the pressure gradient $(\Delta P /$ $\Delta Z$ ), flow, and pressure are illustrated. The methods of measuring the duration of systole and the duration of ejection are illustrated by the crosshatched and by the stippled areas respectively. In beats $B$ and $C$, in which these measurements are illustrated, the duration of total systole is essentially unchanged, although both the stroke volumes and the duration of ejections are quite different. duration of ejection, the preejection period, and the duration of systole versus the stroke volume, and appears from the top down on the left side of Fig. 2. Comparison of these graphs reveals a much wider variation in both the duration of systole and preejection period than in the duration of ejection for a given stroke volume. The range of duration of systole for each patient is listed in Table II, column 2. The duration of systole is influenced very little by stroke volumes exceeding $15 \mathrm{~cm}^{3}$. This finding is illustrated further in Fig. $2 c$ (right) by a plot of the same data from patient R.P. in whom a wide range of stroke volumes were observed. For beats greater than $15 \mathrm{~cm}^{3}$ the duration of total systole remained approximately $0.34 \mathrm{sec}$ with a variation of only $0.04 \mathrm{sec}$, despite a range in stroke volume up to $108 \mathrm{~cm}^{3} /$ beat. Table III, column 2 lists the correlation coefficients for the relation of stroke volume to the duration of systole. A poor individual (range $r=0.13$ $0.80)$ and over-all correlation $(r=0.41)$ is obvious. Individual linear regression equations computed from the stroke volume and duration of total systole demonstrated that the slope was quite small, and in a few patients the slopes were actually negative. As noted previously there was considerable variation in the duration of systole among individual patients. In an attempt to explain these variations the average duration of systole was computed for each patient and correlated with the average heart rate (Table I, column 7) and New York Heart Classification (Table I, column 6). The correlation coefficient for the duration of systole and heart rate was $r=0.47$ and for the New York Heart Classification $r=0.56$.

As can be seen in Fig. $2 a$ the relationship be- tween duration of ejection and the stroke volume appears to be curvilinear. The individual correlation coefficients range from $r=0.81$ to 0.96 with a mean value of $r=0.85$ (Table III, column 5). Since graphs of the data demonstrated a nonlinear relationship, the data were fitted to several types of curves for which the mathematical properties are well known. Plotting the data on logarithmic paper produced almost linear relationships. Correlation coefficient between the $\log _{e} \mathrm{SV}$ and $\log _{\mathrm{e}} \mathrm{DE}$ were in general higher than the corresponding correlation computed directly from the linear data in 11 of the 13 patients; an over-all correlation of $r=0.91$ was found. The logarithmic regression equation for each patient appears in Table III, column 7. The equation $\log _{\mathrm{e}} \mathrm{DE}=$ $2.9118 \log _{\mathrm{e}} \mathrm{SV}+8.3863$ was obtained for the entire group. This equation was used to construct a graph relating stroke volume to duration of ejection and appears in Fig. 3 as the dark line. The crosshatched area represents 2 SEE. Other nonlinear relationships were tested, including: SV vs. $\mathrm{DE}^{3}, \mathrm{SV}^{3}$ vs. $\mathrm{DE}, \mathrm{SV}^{3}$ vs. $\mathrm{DE}^{3}, \log _{\mathrm{e}} \mathrm{SV}$ vs. $\mathrm{DE}$, and $\mathrm{SV}$ vs. $\log _{\mathrm{e}} \mathrm{DE}$, but the correlations obtained were not as good as those from the $\log _{\mathrm{e}} \mathrm{SV}$ vs. $\log _{\mathrm{e}} \mathrm{DE}$ relationship.

Correlation coefficients relating the duration of ejection to the peak power, peak flow, and stroke work are listed in columns $6-8$ of Table IV. These correlations were similar but in most cases not as good as those obtained with stroke volume. Plots of these data also demonstrated a curvilinear relationship. The group correlation coefficients for the logarithmic relation between the duration of ejection and stroke work, peak power, and peak flow were $r=0.84,0.83$, and 0.88 respectively. 


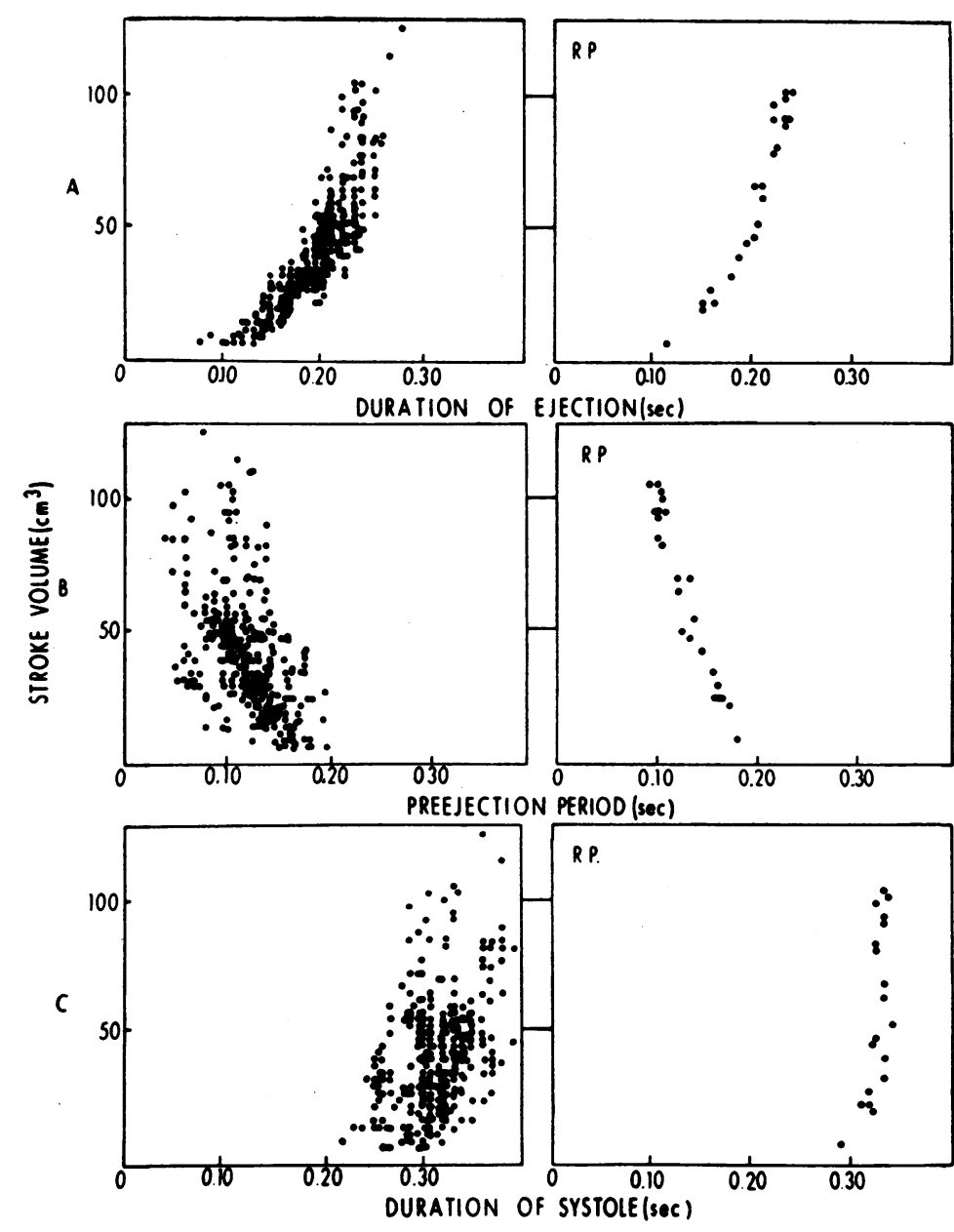

Figure 2 Stroke volume is shown on the ordinate plotted against duration of ejection in panel $A$, preejection period in panel $B$, and duration of systole in panel $C$. The left half of the figure shows the data from all 13 patients. The right half of the figure shows the data from patient R.P. The curves relating stroke volume to duration of ejection for each patient fall close together in contrast to those relating stroke volume to preejection period and duration of systole. Duration of ejection appears to have a curvilinear relationship with stroke volume. The duration of systole changes little with increasing stroke volume above approximately $15 \mathrm{~cm}^{3}$. The preejection period, therefore, varies inversely with stroke volume.
Peak power was usually achieved during the first $40 \%$ of the ejection period except in patients L.S. and W.H. but varied more from beat to beat than the per cent of flow during the first half of ejection. In patients M.B., R.Y., and J.N. there was a clear inverse relationship between the time when peak power occurred and the magnitude of the peak power achieved, i.e., the larger the peak power the earlier it occurred during ejection.

Plots of stroke volume against preejection period (see Fig. 2) demonstrated a clear inverse relationship but with considerable variation from patient to patient (Table III, column 4). Although the individual correlation coefficients $(r=0.75$ .0 .97 ) were good, the overall correlation was only $r=0.53$. Thus most of the variation from patient to patient in the duration of systole appeared to be in the preejection period rather than in the duration of ejection.
In Fig. 4 the relation between stroke volume and previous $\mathrm{RR}$ interval for three individual patients (M.B., J.N., L.D.) is illustrated. Note that the slopes of the data are quite different for each patient. Table IV, column 3 gives the correlation based on linear regression between stroke volume and previous $\mathrm{RR}$ interval. These correlation coefficients ranged from $r=0.53$ to $r=0.93$ and were positive in all cases. Correlation coefficients based on a logarithmic regression were not significantly improved. In addition to the variation in correlation coefficient from one patient to another, the slopes differed considerably, and so the over-all correlation for the 13 patients was $r=0.57$. In order to compare our data with those in previous reports, stroke volume was correlated with the theoretical heart rate calculated from each preceding cycle length. Fig. 5 shows a plot of these data for the whole group and one individual patient 


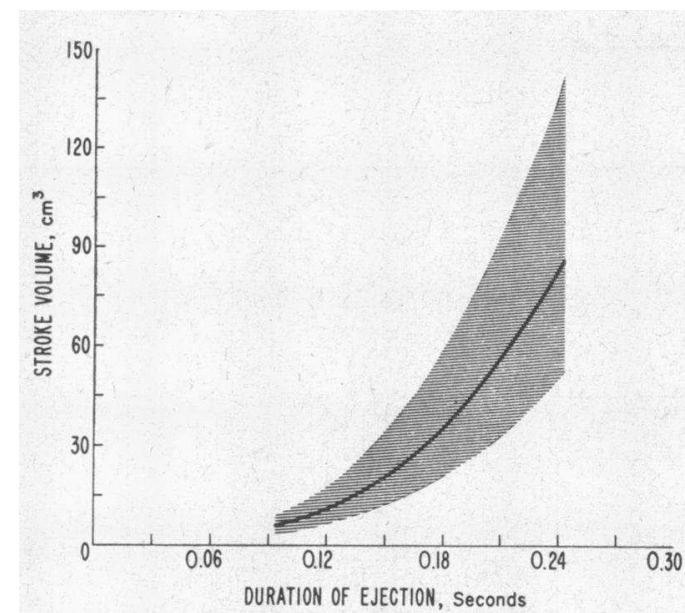

FIGURE 3 The dark line represents mean values obtained from a logarithmic regression equation calculated from the stroke volume (SV) and duration of ejection (DE) $\left(\log _{e} \mathrm{DE}=2.9118 \mathrm{Log}_{\odot} \mathrm{SV}+8.3863\right)$. The crosshatched area represents 2 SEE on either side of the line.

(R.Y.). Again individual variation in both slopes and intercepts resulted in a poor over-all correlation, $r=0.58$, Table IV, column 1 . Although there was considerable scatter, individual plots demonstrated a linear and inverse relationship between stroke volume and heart rate.

Duration of ejection was directly proportional to previous RR interval (Fig. 6a) and appeared

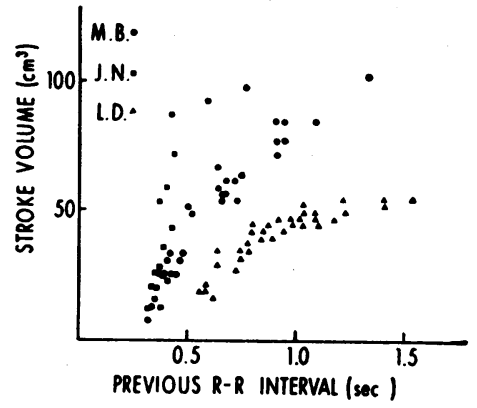

FIgURE 4 Plot of stroke volume versus previous RR interval for individual beats from patients M.B., J.N., and L.D. The relationship is curvilinear, and there is wide variation in the slope. The steepest slope is seen in patient J.N. with mitral stenosis for whom the relationship is least curved.

curvilinear while duration of ejection varied inversely in a roughly linear fashion with theoretical heart rate (Fig. $6 b$ ).

In six patients continuous pressure-flow data were available, and a negative correlation was found between the stroke volume of a particular beat and the cycle length of the second preceding beat. The coefficient of multiple correlation relating the two previous RR intervals to the stroke volume was determined. The results are listed in Table IV, column 4. In each case the correlation was improved over that for stroke volume and the first

TABLE III

Relationships between Stroke Volume and Phases of Systole

\begin{tabular}{|c|c|c|c|c|c|c|}
\hline Patient & $\begin{array}{c}\text { Mean } \\
\text { stroke } \\
\text { volume }\end{array}$ & $\begin{array}{l}\text { Stroke } \\
\text { volume } \\
\text { vs. } \\
\text { duration } \\
\text { systole }\end{array}$ & $\begin{array}{l}\text { Stroke } \\
\text { volume } \\
\text { vs. } \\
\text { preejection } \\
\text { period }\end{array}$ & $\begin{array}{l}\text { Stroke } \\
\text { volume } \\
\text { vs. } \\
\text { duration } \\
\text { ejection }\end{array}$ & $\begin{array}{c}\log _{e} \\
\text { stroke } \\
\text { volume } \\
\text { vs. } \log _{e} \\
\text { duration } \\
\text { ejection }\end{array}$ & $\begin{array}{c}\begin{array}{c}\log _{e} \text { stroke volume }(x) \\
\log _{\mathrm{e}} \text { duration ejection }(y)\end{array} \\
\text { Regression equation }\end{array}$ \\
\hline & $\mathrm{cm}^{3}$ & $r$ & $r$ & $r$ & $r$ & \\
\hline J. S. & 33 & 0.26 & 0.75 & 0.88 & 0.88 & $y=2.9836 x+8.1991$ \\
\hline M. B. & 54 & 0.80 & 0.92 & 0.96 & 0.99 & $y=2.4735 x+7.9298$ \\
\hline L. S. & 29 & 0.50 & 0.95 & 0.93 & 0.97 & $y=2.9234 x+8.3169$ \\
\hline G. P. & 18 & 0.13 & 0.91 & 0.87 & 0.94 & $y=3.4302 x+9.1508$ \\
\hline W. J. & 28 & 0.71 & 0.85 & 0.93 & 0.95 & $y=2.9023 x+8.3696$ \\
\hline R. J. & 80 & 0.29 & 0.81 & 0.82 & 0.80 & $y=3.4956 x+9.2512$ \\
\hline R. Y. & 34 & 0.79 & 0.89 & 0.95 & 0.98 & $y=2.6809 x+7.8101$ \\
\hline S. D. & 39 & 0.28 & 0.89 & 0.92 & 0.95 & $y=3.7313 x+9.8572$ \\
\hline L. D. & 41 & 0.21 & 0.80 & 0.81 & 0.85 & $y=2.5360 x+8.9900$ \\
\hline H. H. & 38 & 0.49 & 0.92 & 0.94 & 0.95 & $y=3.1483 x+8.7870$ \\
\hline R. P. & 64 & 0.67 & 0.97 & 0.95 & 0.99 & $y=3.3963 x+9.5516$ \\
\hline W. H. & 37 & 0.45 & 0.95 & 0.94 & 0.97 & $y=4.2085 x+10.4502$ \\
\hline J. N. & 37 & 0.80 & 0.97 & 0.96 & 0.97 & $y=3.2686 x+9.3715$ \\
\hline All & 41 & 0.41 & 0.53 & 0.85 & 0.91 & $y=2.9118+8.3863$ \\
\hline
\end{tabular}


TABLE IV

Relationships between Various Hemodynamic Parameters

\begin{tabular}{|c|c|c|c|c|c|c|c|}
\hline Patient & $\begin{array}{c}\text { Stroke } \\
\text { volume } \\
\text { vs. } \\
\text { heart } \\
\text { rate }\end{array}$ & $\begin{array}{c}\text { Stroke } \\
\text { volume } \\
\text { vs. previous } \\
\text { RR } \\
\text { intervals }\end{array}$ & $\begin{array}{c}\text { Stroke } \\
\text { volume } \\
\text { vs. two pre- } \\
\text { vious } R R \\
\text { intervals }\end{array}$ & $\begin{array}{l}\text { Stroke } \\
\text { volume } \\
\text { vs. } \\
\text { pulse } \\
\text { pressure }\end{array}$ & $\begin{array}{c}\text { Peak } \\
\text { power } \\
\text { vs. } \\
\text { duration } \\
\text { ejection }\end{array}$ & $\begin{array}{c}\text { Peak } \\
\text { flow } \\
\text { vs. } \\
\text { duration } \\
\text { ejection }\end{array}$ & $\begin{array}{l}\text { Stroke } \\
\text { work } \\
\text { vs. } \\
\text { duration } \\
\text { ejection }\end{array}$ \\
\hline & $r$ & $r$ & $r$ & $r$ & $r$ & $r$ & $r$ \\
\hline J. S. & 0.67 & 0.67 & 0.92 & 0.93 & 0.87 & 0.87 & 0.89 \\
\hline M. B. & 0.95 & 0.93 & - & 0.94 & 0.97 & 0.98 & 0.97 \\
\hline L. S. & 0.64 & 0.75 & 0.96 & 0.96 & 0.92 & 0.95 & 0.93 \\
\hline G. P. & 0.87 & 0.88 & - & 0.98 & 0.85 & 0.88 & 0.87 \\
\hline W. J. & 0.52 & 0.53 & 0.86 & 0.95 & 0.87 & 0.91 & 0.92 \\
\hline R. J. & 0.85 & 0.84 & - & 0.62 & 0.81 & 0.79 & 0.81 \\
\hline R. Y. & 0.94 & 0.91 & 0.94 & 0.95 & 0.95 & 0.96 & 0.97 \\
\hline S. D. & 0.85 & 0.91 & - & 0.96 & 0.82 & 0.81 & 0.92 \\
\hline L. D. & 0.94 & 0.85 & - & 0.87 & 0.83 & 0.83 & 0.82 \\
\hline H. H. & 0.73 & 0.65 & 0.72 & 0.97 & 0.89 & 0.89 & 0.95 \\
\hline R. P. & 0.75 & 0.70 & - & 0.98 & 0.92 & 0.94 & 0.95 \\
\hline W. H. & 0.69 & 0.72 & 0.86 & 0.97 & 0.90 & 0.93 & 0.93 \\
\hline J. N. & 0.81 & 0.80 & - & 0.84 & 0.95 & 0.95 & 0.96 \\
\hline All & 0.58 & 0.57 & & 0.75 & 0.74 & 0.77 & 0.83 \\
\hline
\end{tabular}

preceding $R R$ interval alone, particularly in four of the patients. No additional improvement in correlation was obtained by using the three previous $\mathrm{RR}$ intervals. The magnitude of the stroke volume of any beat showed little correlation with the stroke volume of the previous beat and the multiple correlation of stroke volume with preceding $R R$ interval and previous stroke volume together did not improve upon that obtained from stroke volume and the two preceding RR intervals.

In two patients L.S. and W.H. a considerable pulse deficit existed during a portion of each recording. Beats which did not open the aortic valve either followed a very short cycle length or followed a short cycle length preceded by a large beat. A group of beats following complete pulse deficits were examined separately in both of these patients. The stroke volumes of these beats ap- peared to be appropriate both to the previous RR interval and to the duration of ejection. Thus no evidence of augmentation of stroke volume due to pulse deficit was demonstrated.

Except for one patient, R.J., a good individual correlation was noted between stroke volume and pulse pressure (Table IV, column 5). The reason for this finding in R.J. was not apparent from inspection of the pressure-flow recordings. The correlation coefficient for the group was $r=0.75$ due to individual variation.

\section{DISCUSSION}

Atrial fibrillation alters ventricular filling by the absence of an effective atrial systole and by the presence of variable cycle lengths $(12,13)$. Thus, stroke volume, which by the Frank Starling principle is dependent upon end-diastolic volume, will

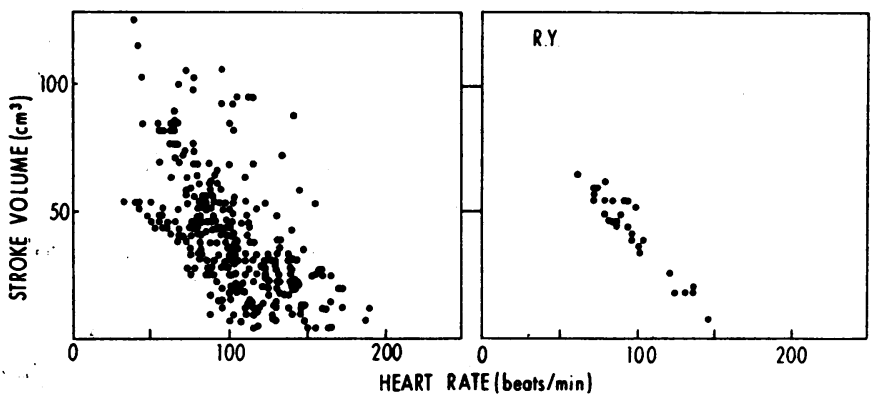

FigURE 5 The relationship of stroke volume and theoretical heart rate calculated from the previous $R R$ interval for individual beats. The data from all 13 patients is shown on the left and that from patient R.Y. on the right. There is wide variation between patients, but for individual patients an apparently linear inverse relation is seen. 


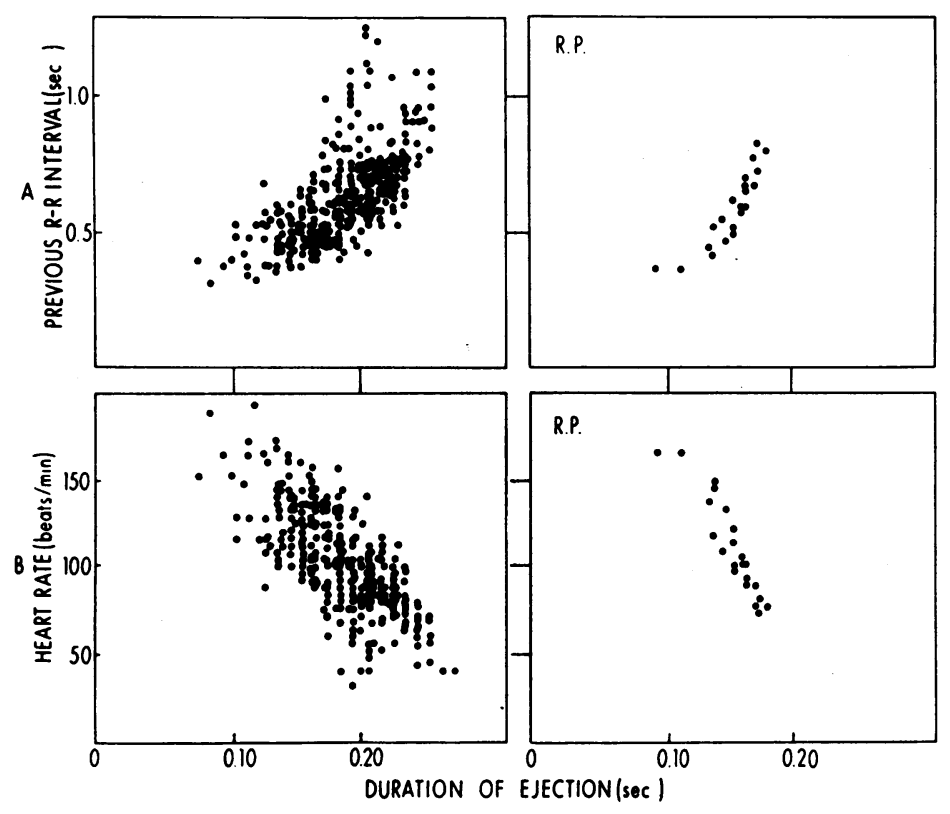

FIGURE 6 A comparison of the relationships between previous $R R$ interval and duration of ejection in the upper panels and that between theoretical heart rate and duration of ejection in the lower panels. The panels on the left show data from all 13 patients, while those on the right show the data from patient R.P. The duration of ejection appears to have a curvilinear relationship with previous RR interval but an approximately linear relationship with theoretical heart rate. vary with preceding cycle length, and for any given cycle length will be less than in sinus rhythm. In addition, the realtionship between cycle length and stroke volume will be modified by the endsystolic volume and will be nonlinear, since ventricular filling does not proceed at the same rate throughout diastole. These factors could account for fluctuations in stroke volume in patients with atrial fibrillation, without invoking any beat to beat change in inotropy.

In addition to effects on ventricular filling, changes in cycle length might be expected to affect ventricular function by altering contractile strength. A relationship between cycle length and myocardial contractility, known as the intervalstrength relation, appears to be a fundamental property of cardiac muscle (14). Studies of this relationship have suggested that changes in cycle length have both positive and negative inotropic effects (15). The intensity and time course of these two effects determine the observed changes in contractility when the frequency of contraction is changed. Furthermore, the influence of any particular abrupt change in frequency of contraction appears to extend with diminishing intensity over subsequent cycles. Thus, if the interval strength relation is an important determinant of ventricular function in atrial fibrillation, the random nature of changes in cycle length will mean that the contractility of a particular beat is gov- erned not only by the preceding cycle length but also by the lengths of several previous cycles. If these considerations apply it follows that the stroke volume of any particular beat would be very hard to predict from the preceding cycle length even if end-diastolic volume was known. Because of these complexities, it is not surprising that in the present study the correlation between stroke volume and the previous cycle length varied widely among individuals and was generally mediocre. Of interest is the improved correlation found when stroke volume and the length of the two previous cycles were subjected to multivariate analysis.

From electrokymographic studies of ventricular volume in patients with atrial fibrillation, Dodge, Kirkham, and King (16) suggested that beats initiated from large end-diastolic volumes produced large stroke volumes and therefore small ventricular end-systolic volumes. After such beats ventricular filling was initiated at a small ventricular volume, and so for any particular cycle length the following end-diastolic volume was relatively small. Multivariate analysis was performed to examine the correlation of stroke volume of any particular beat with the cycle length and stroke volume of the preceding beat, but the correlation coefficients obtained were less than those found for stroke volume and the two preceding RR intervals.

The stroke volume of beats after complete pulse deficits did not appear to be larger or smaller 
than might be expected from their preceding cycle lengths. Since it has been observed that paired electric stimulation produces an increase in stroke volume, it is interesting that in beats following a complete pulse deficit no change in stroke volume was observed (17). Thus, in atrial fibrillation beats producing no aortic blood flow do not form a separate population, but merely represent one end of a spectrum of beats of all sizes.

When stroke volume was plotted against a theoretical heart rate represented by the cycle length for each beat, the relationship was noted to be very similar to that seen when heart rate in man is altered artificially by pacing $(18,19)$. Ross, Linhart, and Braunwald have shown that when the human heart is paced at rest, cardiac output is fairly constant until rates approaching. 120 beats/min are reached (18). The predicted cardiac outputs represented by stroke volume and theoretical heart rate for each beat in several of our patients behaved in the same way.

One of the primary aims of this study was to redefine the relationship of stroke volume and the subintervals of systole in patients with atrial fibrillation. Much of the existing information about the determinants of the duration of the phases of systole has come from experimental work in animals in which heart rate, stroke volume, and blood pressure could be varied or controlled independently (20-22). These studies have shown that the duration of ejection varies directly with stroke volume, but that changes of stroke volume have little or no effect on the duration of total systole. Previous work in man has involved the use of drugs $(23,24)$, exercise $(25-27)$, or other maneuvers (28) in individual subjects, comparisons of patients with different diseases (29), or the statistical analysis of pooled single measurements from large numbers of individuals $(27,28$, $30,31)$. In studies of this type the inotropic background will vary from one individual to another. Furthermore, pooled data from a large group of individuals is likely to show a different relationship between, for example, duration of ejection and cycle length from that shown by serial measurements made in one individual with varying cycle lengths. In pooled normal data the naturally occurring faster heart rates will tend to be associated with higher cardiac outputs and greater sympathetic background as well as shorter filling pe- riods. This difficulty arises particularly when exercise is used to provide a range of heart rates with which to study the phases of systole. If the slope of the relationship of one variable with another is not altered by an intervention such as exercise, but the position of the curve is shifted; then the regression derived from pooling all the data before and after the intervention will be different from the regressions which are obtained from treating the data separately. This appears to be the explanation for the differences in slope found in the relationship between heart rate and ejection time in previous studies $(27-29,32)$.

In the present study, the duration of ejection correlated closely with stroke volume in a given patient over a wide range of stroke volumes. This finding is presumably related to the fact that changes in cycle length were not produced by exercise or other maneuvers which influence the inotropic background. The variation which exists in this relationship for all 13 subjects (Fig. 2) is almost completely due to small differences in the slope and position of the curves for individual patients. The relation of duration of ejection to heart rate will depend critically on the relationship between stroke volume and heart rate, and cardiac output.

The lack of variation in the duration of systole with changes of stroke volume results in an inverse relationship between the duration of the preejection period and stroke volume in patients with atrial fibrillation. The preejection period includes the time between the onset of depolarization and mechanical systole and the isovolumetric contraction period. The isovolumetric contraction period depends on the rate of rise of left ventricular pressure and the pressure at which the aortic valve opens. The rate of rise of left ventricular pressure, assuming a constant inotropic state, will depend upon the end-diastolic volume. In atrial fibrillation, therefore, a beat with a large stroke volume and a long preceding cycle length will be associated with a lower pressure at which the aortic valve is open and a greater end-diastolic volume. Both of these factors will tend to shorten the preejection period. The relatively constant duration of systole over a wide range of stroke volume in individual patients in this study could therefore be regarded as evidence for a relatively constant state of inotrophy during the period of 
recording. These studies in man are entirely consistent therefore with the previously noted studies in dogs in which the relationship of stroke volume to the duration of the phases of systole was studied under controlled conditions (20).

Dodge, Kirkham, and King (16) noted variations in the duration of ventricular systole with varying pulse pressure in patients with atrial fibrillation, but their measurement of systole from heart sound recordings is not comparable to ours. The interval between the onset of the first and second heart sounds includes the duration of ejection and a part of the isovolumic contraction period. How much of the isovolumic period is included in this estimate of systole depends on the characteristics of the first heart sound in the subject being studied.

The ranges of values for duration of ejection, cycle length, and stroke volume in this study appear to be similar to those previously reported from the use of other methods. The use of the duration of forward flow as the duration of ejection gives a slightly smaller value for duration of ejection than the central aortic pressure tracing. Duration of total systole will be a little shorter than that obtained from the electrocardiogram and the phonocardiogram because of the use of the end of forward flow instead of aortic valve closure. Stroke work, peak flow, and peak power are controlled chiefly by stroke volume and therefore have the same general relationship to the phases of systole as does stroke volume. Thus the discussion of these relationships between the duration of systole and ejection and stroke volume will also be applicable to these parameters.

The contour of the flow pulse was similar in configuration to that obtained from normal subjects in this laboratory $(6,7)$ and in others $(8,9)$ with the pressure gradient technique. In the three patients with mitral insufficiency the flow was not abnormally small during the last part of ejection as recently described by Elkins, Morrow, Vasco, and and Braunwald (33). These investigators used an electromagnetic flowmeter at surgery to measure aortic blood flow. Their findings may be due to more severe mitral insufficiency in the patients which they have studied than in the three reported here. The relationship between the duration of preejection and stroke volume was qualitatively the same in the three patients with mitral regurgi- tation and the rest of the group. The effect of loss of ventricular volume into the left atrium before the aortic valves are opened is presumably compensated for by an increased rate of rise of left ventricular pressure possibly as a result of increased left ventricular end-diastolic pressure.

\section{ACKNOWLEDGMENTS}

The authors are grateful to Mrs. Corinna T. Walker and Miss Judith C. Rembert for technical assistance and to Mr. Frank Starmer and Mr. Phillip McHale for help with the data analysis.

This study was supported in part by a U. S. Public Health Service Research Grant No. HE-09711 and by the Myocardial Infarction Research Unit Contract No. $\mathrm{PH}-43-67-1440$. Dr. Greenfield is the recipient of a Career Development Award from the U. S. Public Health Service 1-K3-HE-28,112. Dr. Wallace is the recipient of a Career Development Award from the U. S. Public Health Service 2-K3-HE-19,949.

\section{REFERENCES}

1. McIntosh, H. D., and J. Morris, Jr. 1966. The hemodynamic consequences of arrhythmias. Progr. Cardiovascular Diseases. 8: 330.

2. Fry, D. L. 1959. The measurement of pulsatile blood flow by the computed pressure gradient technique. IRE (Inst. Radio Engrs.) Trans. Med. Electron. ME-6: 259.

3. Greenfield, J. C., Jr., D. J. Patel, A. J. Mallos, and D. L. Fry. 1962. Evaluation of Kolin type electromagnetic flowmeter and the pressure gradient technique. J. Appl. Physiol. 17: 372 .

4. Greenfield, J. C., Jr., and D. L. Fry. 1965. Relationship between instantaneous aortic flow and the pressure gradient. Circulation Res. 17: 340 .

5. Hernandez, R. R., J. C. Greenfield, Jr., and B. W. McCall. 1964. Pressure-flow studies in hypertrophic subaortic stenosis. J. Clin. Invest. 43: 401.

6. Greenfield, J. C., Jr., R. L. Cox, R. R. Hernandez, C. Thomas, and F. W. Schoonmaker. 1967. Pressureflow studies in man during the valsalva maneuver with observations on the mechanical properties of the ascending aorta. Circulation. 35: 653.

7. Snell, R. E., J. M. Clements, D. J. Patel, D. L. Fry, and P. C. Luchsinger. 1965. Instantaneous blood flow in the human aorta. J. Appl. Physiol. 20: 691.

8. Porje, I. G., and B. Rudewald. 1961. Hemodynamic studies with differential pressure technique. Acta Physiol. Scand. 51: 116.

9. Gabe, I. T., J. Karnell, I. G. Porjé, and B. Rudewald. 1964. The measurement of input impedance and apparent phase velocity in the human aorta. Acta Physiol. Scand. 61 : 73.

10. Greenfield, J. C., Jr. 1966. The pressure gradient technique. Methods Med. Res. 11: 83.

11. Greenfield, J. C., Jr., and D. L. Fry. 1962. Measurement errors in estimating the aortic blood velocity 
by the pressure gradient. J. Appl. Physiol. 17: 1013.

12. Samet, P., W. H. Bernstein, S. Levine, and A. Lopez. 1965. Hemodynamic effects of tachycardias produced by atrial and ventricular pacing. Am. J. Med. 39: 905 .

13. Benchimol, A., J. G. Ellis, and E. G. Dimond. 1965. Hemodynamic consequences of atrial and ventricular pacing in patients with normal and abnormal hearts. Am. J. Med. 39: 911.

14. Koch-Weser, J., and J. R. Blinks. 1963. The influence of the interval between beats on myocardial contractility. Pharmacol. Rev. 15: 601.

15. Blinks, J. R., and J. Koch-Weser. 1961. Analysis of the effects of changes in rate and rhythm upon myocardial contractility. J. Pharmacol. Exptl. Therap. 134: 373.

16. Dodge, H. T., F. T. Kirkham, Jr., and C. V. King. 1957. Ventricular dynamics in atrial fibrillation. Circulation. 15: 335.

17. Braunwald, E., J. Ross, Jr., P. L. Frommer, J. F. Williams, Jr., E. H. Sonnenblick, and J. H. Gault. 1964. Clinical observations on paired electrical stimulation of the heart. Am. J. Med. 37: 700.

18. Ross, J., Jr., J. W. Linhart, and E. Braunwald. 1965. Effects of changing heart rate in man by electrical stimulation of the right atrium. Circulation. 32: 549.

19. Bevegard, S., B. Jonsson, I. Karlof, H. Lagergren, and E. Sowton. 1967. Effect of changes in ventricular rate on cardiac output and central pressures at rest and during exercise in patients with artificial pacemakers. Cardiovascular Res. 1: 21.

20. Wallace, A. G., J. H. Mitchell, N. S. Skinner, and S. J. Sarnoff. 1963. Duration of the phases of left ventricular systole. Circulation Res. 12: 611.

21. Braunwald, E., S. J. Sarnoff, and W. N. Stainsby. 1958. Determinants of duration and mean rate of ventricular ejection. Circulation Res. 6: 319.

22. Katz, L. N. 1927. Observations on the dynamics of ventricular contractions in the heart-lung preparation. Am. J. Physiol. 80: 470.
23. Weissler, A. M., W. G. Gamel, H. E. Grode, S. Cohen, and C. D. Schoenfeld. 1964.. The effect of digitalis on ventricular ejection in normal human subjects. Circulation. 29: 721.

24. Harris, W. S., C. D. Schoenfeld, R. H. Brooks, and A. M. Weissler. 1966. Effect of beta adrenergic blockade on the hemodynamic responses to epinephine in man. Am. J. Cardiol. 17: 484.

25. Frank, M. N., and W. B. Kinlaw. 1962. Indirect measurement of isovolumetric contraction time and tension period in normal subjects. Am. J. Cardiol. $10: 800$.

26. Bowen, W. P. 1904. Changes in heart rate, blood pressure, and duration of systole resulting from bicycling. Am. J. Physiol. 11: 59.

27. Jones, W. B., and G. L. Foster. 1964. Determinants of duration of left ventricular ejection in normal young men. J. Appl. Physiol. 19: 279.

28. Weissler, A. M., L. C. Harris, and G. D. White. 1963. Left ventricular ejection time index in man. J. Appl. Physiol. 18: 919.

29. Weissler, A. M., R. G. Peeler, and W. H. Roehl, Jr. 1961. Relationships between left ventricular ejection time, stroke volume, and heart rate in normal individuals and patients with cardiovascular disease. $\mathrm{Am}$. Heart J. $62: 367$.

30. Katz, L. N., and H. S. Feil. 1923. Clinical observations on the dynamics of ventricular systole: $I$. Auricular fibrillation. Arch. Intern. Med. 32: 672.

31. Lombard, W. P., and O. M. Cope. 1926. The duration of the systole of the left ventricle of man. Am. J. Physiol. 77: 263.

32. Agress, C. M., S. Wegner, S. Nakakura, E. H. Lehman, Jr., and L. Chait. 1965. Comparison of the ejection time-heart rate relationships in normal and ischemic subjects. Japan. Heart J. 6: 497.

33. Elkins, R. C., A. G. Morrow, J. S. Vasko, and E. Braunwald. 1967. The effects of mitral regurgitation on the pattern of instantaneous aortic blood flow. Circulation. 36: 45. 